\title{
NMR conformational study of the lanthanide(III) complexes of DOTA in aqueous solution
}

\author{
M.P.M. Marques ${ }^{a}$, C.F.G.C. Geraldes ${ }^{a}$, A.D. Sherry ${ }^{b}$, A.E. Merbach ${ }^{\text {, }}$, H. Powell ${ }^{c}$, \\ D. Pubanz ${ }^{\text {c }}$, S. Aime ${ }^{\mathrm{d}}$, M. Botta ${ }^{\mathrm{d}}$ \\ a Biochemistry Department, University of Coimbra, 3049 Coimbra, Portugal \\ ${ }^{\mathrm{b}}$ Chemistry Department, University of Texas at Dallas, Richardson, TX, USA \\ ${ }^{\mathrm{c}}$ Institut de Chimie Minérale et Analytique, Place du Château 3, 1005 Lausanne, Switzerland \\ `Dipartimento Chimica Inorganica, Fisica e Materiali, Università di Torino, P. Giuna 7, Torino, Italy
}

\begin{abstract}
Variable temperature NMR spectroscopy studies of lanthanide(III) complexes with 1,4,7,10-tetraazacyclododecane- $N^{\prime}, N^{\prime}, N^{\prime \prime}, N^{\prime \prime}$ tetraacetic acid (DOTA) provide evidence of the presence of two isomeric forms in aqueous solution. An NMR study was performed in order to gain structural information on the two isomeric species, using a fitting procedure of calculated to experimental dipolar contributions to the paramagnetic shifts. The two isomers show to have identical macrocyclic ring conformations and differ only in the coordination or orientation of the acetate arms of the ligand, yielding either square prismatic and square anti-prismatic coordination geometries, or octadentate and heptadentate coordinations of the ligand relative to the lanthanide ion. Analysis of the dipolar shifts is consistent with both types of acetate conformational equilibria.
\end{abstract}

Keywords: Nuclear magnetic resonance; Aqueous solution; Chelates

\section{Introduction}

The polyfunctional macrocyclic ligands, combining the advantages of variable cavity size and rigidity with the presence of different ionizable functions, have been the object of numerous investigations, on account of their unique coordination properties, namely their selectivity and $\mathrm{pH}$ sensitive complexing abilities [1,2]. Their lanthanide chelates have been shown to behave as effective NMR shift and/or relaxation probes in aqueous solution, which allows them to be used in structural studies of biomolecules and also as contrast agents in medical diagnosis by nuclear magnetic resonance imaging [3-5].

The 1,4,7,10-tetraazacyclododecane- $N, N^{\prime}, N^{\prime \prime}, N^{\prime \prime \prime}$ tetraacetic acid (DOTA) is a polyaza-polyacetic ligand, that has been shown to form stable complexes with the trivalent lanthanide cations in aqueous solution [6]. These complexes present axial symmetry and are rigid on the NMR time-scale, two features that are rarely met in lanthanide solution chemistry. The study of the significant shifts induced by the paramagnetic lanthanide ions on the nuclear magnetic resonances of the ligand (lanthanide-induced shifts, LIS) can help to determine the structure of the corresponding chelates [7]. Desreux and co-workers first studied the Ln(DOTA) ${ }^{-}$complexes in aqueous solution, using both ${ }^{1} \mathrm{H}$ and ${ }^{13} \mathrm{C}$ dynamic NMR spectroscopy [8], having detected a very slow kinetics of formation for these species, at room temperature, that has been partially explained by their unusual stereodynamic behaviour. The solution structure and dynamics of these chelates have lately been the subject of thorough investigation by different workers [9-11]. NMR studies lead to the detection of two isomeric species, whose relative abundance varies markedly along the lanthanide series. These two isomers, represented here by $A$ and $B$, have, respectively, higher and lower magnetic susceptibility values. The existence of two isomers in solution has also been detected, both by NMR and luminescence techniques, for the $\mathrm{Eu}(\mathrm{DOTA})^{-}$chelate $[12,13]$, as well as for the Ln(DOTMA $)^{-}$complexes [13] DOTMA $=[1 \mathrm{R}-$ $\left.\left(1 \mathrm{R}^{*}, 4 \mathrm{R}^{*}, 7 \mathrm{R}^{*}, 10 \mathrm{R}^{*}\right)\right]-\alpha, \alpha^{\prime}, \alpha^{\prime \prime}, \alpha^{\prime \prime \prime}$-tetra-methyl-1,4,7,10tetraazacyclododecane- $N, N^{\prime}, N^{\prime \prime}, N^{\prime \prime}$-tetraacetic acid).

In this work, the conformational behaviour of the two isomeric species present in aqueous solution was 
investigated, through a systematic NMR study of the whole series of the $\operatorname{Ln}(\mathrm{DOTA})^{-}$chelates, as a function of $\mathrm{pH}$, temperature and salt concentration, using a fitting procedure of calculated to experimental dipolar contributions to the measured ${ }^{1} \mathrm{H}$ and ${ }^{13} \mathrm{C}-\mathrm{NMR}$ paramagnetic shifts.

\section{Experimental}

The ligand DOTA was synthesized and purified as described elsewhere $[8,14]$. Hexahydrated lanthanide chlorides were purchased from Aldrich Chem. Co. Lanthanide complexes were prepared in aqueous solution, at $0.01 \mathrm{~mol} \mathrm{dm}^{-3}$ concentration, by adding stoichiometric amounts of the macrocyclic ligand to stock solutions of the corresponding chlorides, following the procedure reported by Desreux [8]. The $\mathrm{pH}$ of the solutions was adjusted with $\mathrm{DCl}$ and $\mathrm{CO}_{2}$-free $\mathrm{NaOD}$. NMR spectra were recorded on JEOL FX-200, VARIAN XL-200 and UNITY-500, and BRUKER AMX500 Fourier transform spectrometers (operating at external fields of $4.7 \mathrm{~T}$ and $11.8 \mathrm{~T}$, respectively). Either TSP- $\mathrm{d}_{4}$ (tetradeuterated sodium trimethylsylil-propionate) or 2-methyl-2-propanol, and 1,4-dioxane were used as internal references, respectively for the ${ }^{1} \mathrm{H}$ and ${ }^{13} \mathrm{C}$ -
NMR spectra. The computer program PDIGM [15] was used to determine the agreement between the observed and the calculated LIS values, (based on an axial symmetry model). Molecular modelling was performed using PCMODEL (Serena Software).

\section{Results and discussion}

The proton NMR spectra of the $\operatorname{Ln}(\text { DOTA })^{-}$chelates in aqueous solution show two sets of resonances, with different intensities, corresponding to two different coordination geometries for the lanthanide cation, in contrast to what has been observed for the $\operatorname{Ln}(\mathrm{DOTP})^{5-}$ complexes (DOTP $=1,4,7,10$-tetraazacyclododecane$\mathrm{N}, \mathrm{N}^{\prime}, \mathrm{N}^{\prime \prime}, \mathrm{N}^{\prime \prime \prime}$-tetra-(methylene phosphonate), for which only one set of signals is observed, in agreement with the existence of just one possible conformation in solution for these species [16]. The relative abundance of each of the two isomers of the Ln(DOTA $)^{-}$complexes changes along the lanthanide series, one of them being more stable for the larger cations $\left(\mathrm{Ce}^{3+}\right.$ to $\left.\mathrm{Pr}^{3+}\right)$ while the other predominates for the heavier, smaller ions $\left(\mathrm{Nd}^{3+}\right.$ to $\left.\mathrm{Yb}^{3+}\right)$. Table 1 contains the LIS values (at different temperatures) relative to the ${ }^{1} \mathrm{H}$ and ${ }^{13} \mathrm{C}$ signals of the two isomeric species of the $\operatorname{Ln}(\text { DOTA })^{-}$chelates.

Table 1

Paramagnetic NMR lanthanide-induced shifts (LIS) $\left({ }^{1} \mathrm{H}\right.$ and ${ }^{13} \mathrm{C}$ ) relative to the $\mathrm{Ln}$ (DOTA) ${ }^{-}$chelates in aqueous solution. (Values obtained at $20^{\circ} \mathrm{C}$ and $\mathrm{pH}=7$, for an external magnetic field of $11.8 \mathrm{~T}$. A and $\mathrm{B}$ represent, respectively, the isomers having higher and lower magnetic susceptibility values. The negative sign denotes a shift to lower frequencies)

$\begin{array}{ll}\text { Isomer A } & \text { Isomer B }\end{array}$

\begin{tabular}{|c|c|c|c|c|c|c|c|c|c|c|c|c|}
\hline $\mathrm{Ln}^{3+}$ & $\mathrm{H}_{1}$ & $\mathrm{H}_{2}$ & $\mathrm{H}_{3}$ & $\mathbf{H}_{4}$ & $\mathrm{H}_{5}$ & $\mathrm{H}_{6}$ & $\mathbf{H}_{1}{ }^{\prime}$ & $\mathrm{H}_{2}^{\prime}$ & $\mathrm{H}_{3}{ }^{\prime}$ & $\mathrm{H}_{4}^{\prime}$ & $\mathrm{H}_{5}^{\prime}$ & $\mathrm{H}_{6}{ }^{\prime}$ \\
\hline $\mathrm{Ce}^{3+}$ & - & - & - & - & - & - & 4.5 & 2.0 & -1.0 & -13.8 & 6.8 & 3.4 \\
\hline $\mathrm{Pr}^{3+}$ & - & - & - & - & - & - & 10.5 & -0.9 & -3.1 & -28.4 & 16.9 & 7.9 \\
\hline $\mathrm{Nd}^{3+}$ & 8.4 & 0.5 & 0.1 & -26.4 & 16.3 & 3.9 & 6.3 & 4.5 & 3.5 & -11.5 & 11.3 & 3.9 \\
\hline $\mathrm{Sm}^{3+}$ & 0.5 & -1.5 & -1.0 & -6.0 & 4.4 & -0.5 & - & - & - & - & - & - \\
\hline $\mathrm{Eu}^{3+}$ & -18.0 & -3.6 & -9.1 & 31.2 & -19.7 & -12.1 & -3.5 & -10.2 & -12.9 & 10.1 & -8.2 & -4.8 \\
\hline $\mathrm{Tb}^{3+}$ & 134.6 & -98.8 & -102.4 & -405.4 & 256.0 & 79.4 & 80.2 & -75.3 & -75.9 & -243.7 & 176.5 & 61.5 \\
\hline $\mathrm{Dy}^{3+}$ & 161.8 & -102.5 & -110.0 & -477.8 & 308.0 & 107.6 & 108.4 & -77.4 & -74.6 & -295.1 & 220.6 & 83.9 \\
\hline $\mathrm{Ho}^{3+}$ & 84.0 & -59.2 & -58.9 & -246.6 & 158.2 & 49.9 & 50.7 & -39.5 & -40.1 & -140.5 & 100.9 & 38.8 \\
\hline $\mathrm{Er}^{3+}$ & -60.3 & 4.5 & 15.2 & 149.5 & -103.6 & -61.1 & - & - & - & - & - & - \\
\hline $\mathrm{Tm}^{3+}$ & -205.8 & 52.1 & 68.0 & 468.2 & -358.9 & -170.7 & -134.2 & 45.2 & 60.3 & 366.3 & -240.8 & -113.5 \\
\hline \multirow[t]{2}{*}{$\mathrm{Yb}^{3+}$} & -56.0 & 21.1 & 25.6 & 153.7 & -101.5 & -47.9 & -38.3 & 9.0 & 11.2 & 86.3 & -61.9 & -33.9 \\
\hline & \multicolumn{2}{|c|}{$\mathrm{C}_{\mathrm{t}}$} & $\mathrm{C}_{2}$ & \multicolumn{2}{|c|}{$\mathrm{C}_{3}$} & $\mathrm{C}_{4}$ & \multicolumn{2}{|l|}{$\mathrm{C}_{1}^{\prime}$} & $\mathrm{C}_{2}^{\prime}$ & \multicolumn{2}{|l|}{$\mathrm{C}_{3}^{\prime}$} & $\mathrm{C}_{4}^{\prime}$ \\
\hline $\mathrm{Px}^{3+}$ & \multicolumn{2}{|c|}{-} & - & \multirow{2}{*}{\multicolumn{2}{|c|}{-}} & - & \multicolumn{2}{|c|}{-67.4} & -38.1 & \multicolumn{2}{|c|}{-7.1} & -10.9 \\
\hline $\mathrm{Nd}^{3+}$ & \multicolumn{2}{|c|}{-35.3} & -18.1 & & & -3.6 & \multicolumn{2}{|c|}{-46.8} & -28.7 & \multicolumn{2}{|c|}{-17.8} & -20.8 \\
\hline $\mathrm{Sm}^{3+}$ & \multicolumn{2}{|c|}{-1.6} & 6.8 & \multicolumn{2}{|c|}{10.8} & 9.7 & \multicolumn{2}{|c|}{-7.5} & -0.8 & \multicolumn{2}{|c|}{-3.5} & 2.9 \\
\hline $\mathrm{Eu}^{3+}$ & \multicolumn{2}{|c|}{33.0} & 33.5 & \multicolumn{2}{|c|}{25.3} & 26.2 & \multicolumn{2}{|c|}{58.8} & 40.3 & \multicolumn{2}{|c|}{4.2} & 11.2 \\
\hline $\mathrm{Tb}^{3+}$ & \multicolumn{2}{|c|}{-198.4} & 9.7 & \multicolumn{2}{|c|}{403.9} & 505.9 & \multicolumn{2}{|c|}{-} & - & \multicolumn{2}{|l|}{ - } & - \\
\hline $\mathrm{Dy}^{3+}$ & \multicolumn{2}{|c|}{-267.7} & -16.9 & \multicolumn{2}{|c|}{457.4} & 566.4 & \multicolumn{2}{|l|}{-} & - & \multicolumn{2}{|l|}{ - } & - \\
\hline $\mathrm{Ho}^{3+}$ & & 4.3 & 1.0 & \multicolumn{2}{|c|}{256.2} & 302.3 & - & & - & - & & - \\
\hline $\mathrm{Er}^{3+}$ & & 16.6 & 119.8 & & .7 & -214.9 & - & & - & - & & - \\
\hline $\mathrm{Tm}^{3+}$ & - & & - & - & & - & 287.0 & & 81.9 & -2 & & -423.7 \\
\hline $\mathrm{Yb}^{3+}$ & & 3.1 & 31.9 & & & -140.4 & 38.7 & & 10.9 & & & -78.7 \\
\hline
\end{tabular}


Table 2

Experimental and calculated values of the geometrical factor $(G)$ relative to the various structures considered for the Ln(DOTA) ${ }^{-}$chelates in aqueous solution

\begin{tabular}{|c|c|c|c|c|c|c|c|}
\hline \multicolumn{2}{|l|}{$\begin{array}{l}G_{\exp } \\
\mathrm{A}\end{array}$} & \multicolumn{3}{|l|}{$\mathrm{B}_{\mathrm{I}}$} & \multirow{2}{*}{$\begin{array}{l}\begin{array}{l}G_{\text {calc }} \\
\mathrm{A}\end{array} \\
{ }^{\mathrm{a}}(R=3.7 \%, d=1.50)\end{array}$} & \multirow{2}{*}{$\frac{\mathrm{B}_{\mathrm{I}}}{(R=9.6 \%, d=1.39)}$} & \multirow{2}{*}{$\frac{\mathrm{B}_{\mathrm{II}}}{(R=7.6 \%, d=1.20)}$} \\
\hline Nucleus & $\begin{array}{l}\mathrm{Nd}-\mathrm{Yb} \\
(-\mathrm{Tm})\end{array}$ & $\mathrm{Ce}-\mathrm{Eu}$ & $\mathrm{Tb}-\mathrm{Yb}$ & $\begin{array}{l}\mathrm{Pr}-\mathrm{Yb} \\
(-\mathrm{Tm})\end{array}$ & & & \\
\hline $\mathrm{H}_{1}$ & $\begin{array}{c}-2.66 \\
( \pm 0.30)\end{array}$ & $\begin{array}{c}-0.61 \\
( \pm 0.07)\end{array}$ & $\begin{array}{c}-1.77 \\
( \pm 0.20)\end{array}$ & $\begin{array}{c}-1.48 \\
( \pm 0.14)\end{array}$ & $\begin{array}{r}-2.50 \\
( \pm 0.09\end{array}$ & $\begin{array}{c}-1.34 \\
( \pm 0.13)\end{array}$ & $\begin{array}{c}-1.33 \\
( \pm 0.10)\end{array}$ \\
\hline $\mathrm{H}_{2}$ & $\begin{array}{c}1.01 \\
( \pm 0.06)\end{array}$ & - & $\begin{array}{c}0.52 \\
( \pm 0.01)\end{array}$ & $\begin{array}{c}0.50 \\
( \pm 0.04)\end{array}$ & $\begin{array}{c}1.10 \\
( \pm 0.04)\end{array}$ & $\begin{array}{c}0.44 \\
( \pm 0.04)\end{array}$ & $\begin{array}{c}0.30 \\
( \pm 0.02)\end{array}$ \\
\hline $\mathrm{H}_{3}$ & $\begin{array}{c}1.21 \\
( \pm 0.08)\end{array}$ & - & - & $\begin{array}{c}0.51 \\
( \pm 0.06)\end{array}$ & $\begin{array}{c}1.20 \\
( \pm 0.04)\end{array}$ & $\begin{array}{r}0.57 \\
( \pm 0.05)\end{array}$ & $\begin{array}{r}0.35 \\
( \pm 0.03)\end{array}$ \\
\hline $\mathrm{H}_{4}$ & $\begin{array}{c}6.92 \\
( \pm 0.52)\end{array}$ & - & - & $\begin{array}{c}3.20 \\
( \pm 0.33)\end{array}$ & $\begin{array}{c}7.11 \\
( \pm 0.26)\end{array}$ & $\begin{array}{c}3.47 \\
( \pm 0.33)\end{array}$ & $\begin{array}{c}3.30 \\
( \pm 0.25)\end{array}$ \\
\hline $\mathrm{H}_{5}$ & $\begin{array}{c}-4.79 \\
( \pm 0.50)\end{array}$ & $\begin{array}{c}-0.93 \\
( \pm 0.16)\end{array}$ & $\begin{array}{c}-2.66 \\
( \pm 0.09)\end{array}$ & $\begin{array}{c}-2.52 \\
( \pm 0.21)\end{array}$ & $\begin{array}{c}-4.57 \\
( \pm 0.17)\end{array}$ & $\begin{array}{c}-2.23 \\
( \pm 0.21)\end{array}$ & $\begin{array}{c}-2.58 \\
( \pm 0.20)\end{array}$ \\
\hline $\mathrm{H}_{6}$ & $\begin{array}{c}-2.16 \\
( \pm 0.26)\end{array}$ & $\begin{array}{c}-0.47 \\
( \pm 0.06)\end{array}$ & $\begin{array}{c}-1.51 \\
( \pm 0.15)\end{array}$ & $\begin{array}{c}-1.26 \\
( \pm 0.15)\end{array}$ & $\begin{array}{c}-2.15 \\
( \pm 0.08)\end{array}$ & $\begin{array}{c}-1.15 \\
( \pm 0.11)\end{array}$ & $\begin{array}{c}-1.10 \\
( \pm 0.08)\end{array}$ \\
\hline$C_{1}$ & $\begin{array}{c}3.81 \\
( \pm 0.16)\end{array}$ & - & - & $\begin{array}{r}4.70 \\
( \pm 0.24)\end{array}$ & $\begin{array}{r}4.47 \\
( \pm 0.17)\end{array}$ & $\begin{array}{c}2.15 \\
( \pm 0.21)\end{array}$ & $\begin{array}{c}2.74 \\
( \pm 0.21)\end{array}$ \\
\hline$C_{2}$ & $\begin{array}{c}1.14 \\
( \pm 0.12)\end{array}$ & - & - & $\begin{array}{c}2.60 \\
( \pm 0.32)\end{array}$ & $\begin{array}{c}1.03 \\
( \pm 0.04)\end{array}$ & $\begin{array}{r}0.36 \\
( \pm 0.03)\end{array}$ & $\begin{array}{c}1.05 \\
( \pm 0.08)\end{array}$ \\
\hline$C_{3}$ & $\begin{array}{c}-4.28 \\
( \pm 0.48)\end{array}$ & - & - & $\begin{array}{c}-4.64 \\
( \pm 1.16)\end{array}$ & $\begin{array}{c}-5.53 \\
( \pm 0.20)\end{array}$ & $\begin{array}{c}-2.80 \\
( \pm 0.27)\end{array}$ & $\begin{array}{c}-2.90 \\
( \pm 0.22)\end{array}$ \\
\hline$C_{4}$ & $\begin{array}{c}-6.28 \\
( \pm 0.37)\end{array}$ & - & - & $\begin{array}{c}-5.67 \\
( \pm 2.45)\end{array}$ & $\begin{array}{c}-6.92 \\
( \pm 0.26)\end{array}$ & $\begin{array}{c}-2.77 \\
( \pm 0.27)\end{array}$ & $\begin{array}{c}-4.43 \\
( \pm 0.34)\end{array}$ \\
\hline
\end{tabular}

${ }^{a} R$ represents the correlation factor of the calculation performed with the PDIGM program; $d$ represents the distance $(\AA)$ between the lanthanide ion and the plane of the macrocyclic ring.

A

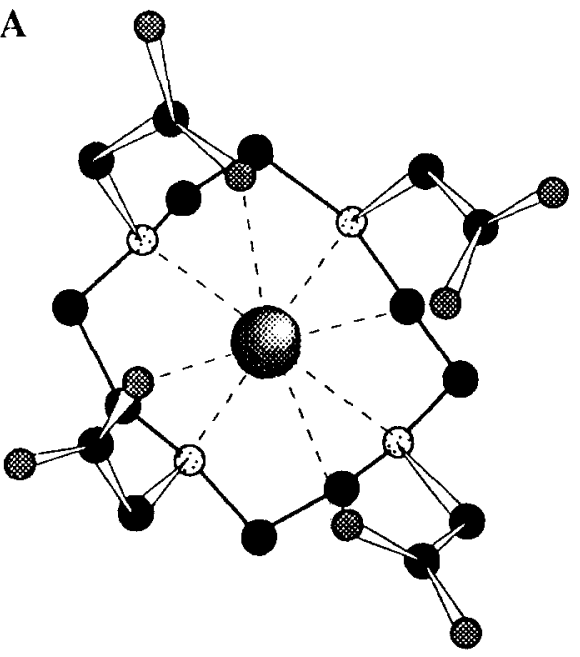

$B_{1}$

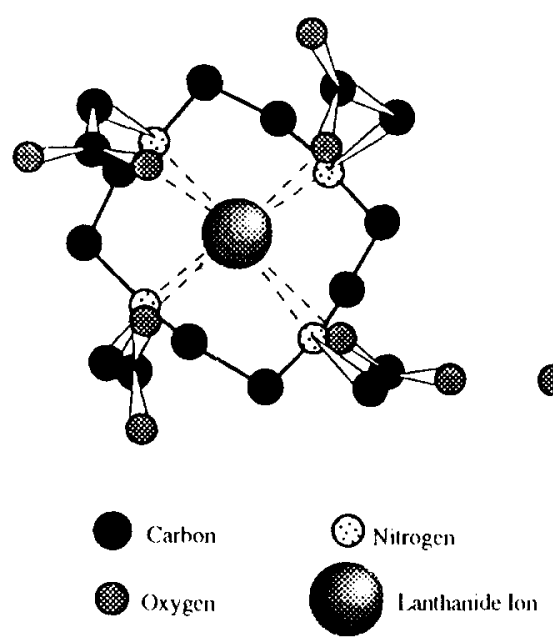

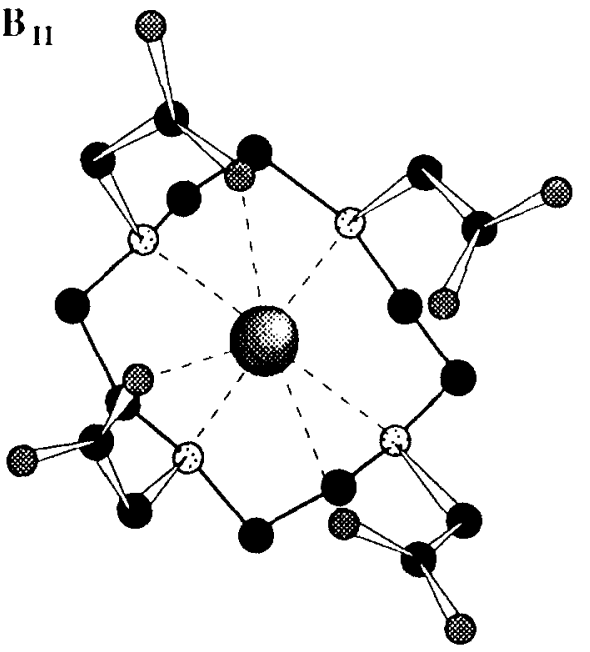

Fig. 1. Schematic representation of the isomeric forms $\left(A, B_{I}\right.$ and $\left.B_{I I}\right)$ of the $\operatorname{Ln}(D O T A)^{-}$chelates, in aqueous solution, according to the proposed structural models.

The contact and pseudo-contact contributions to the LIS values were separated according to the method of Reilley $[17,18]$ and the geometrical factor $(G)$ was determined for each of the complexes. The calculation of the parameter $G$, as well as of the $\mathrm{Ln}-\mathrm{H}$ distances within the complex, were also performed by a fitting procedure of the experimental NMR results to an axial symmetry model of the chelates (based on published X-ray data [19]) (Tables 2 and 3).

A structural model has recently been proposed to account for the conformational behaviour of the Ln(DOTA $)^{-}$complexes in aqueous solution [9-11]: presence of two different isomeric forms, with identical macrocyclic ring conformation and differing only in the 
Table 3

Calculated Ln-H distances $(\AA)$ relative to the $\ln (\text { DOTA })^{-}$chelates, in aqueous solution. (Values corresponding to the best localization of the $\mathrm{Ln}^{3+}$ cation, calculated by the PDIGM program, based on the experimental LIS data relative to each one of the structural models proposed.) Comparison with results due to other workers for the same systems and also with the crystal structure of the Eu(DOTA) - complex

\begin{tabular}{|c|c|c|c|c|c|}
\hline \multirow[t]{4}{*}{ Nucleus } & \multicolumn{5}{|l|}{ DOTA } \\
\hline & \multicolumn{3}{|l|}{$r_{\text {calc }}{ }^{a}$} & \multirow{3}{*}{$\frac{t_{\text {exp }}{ }^{b}}{\mathrm{~Tb}-\mathrm{Ho}}$} & \multirow{3}{*}{$\begin{array}{l}X \text {-ray }{ }^{\circ} \\
\mathrm{Eu}\end{array}$} \\
\hline & A & $\mathrm{B}_{1}$ & $\mathbf{B}_{\mathbf{n}}$ & & \\
\hline & $\mathrm{Nd}-\mathrm{Yb}$ & $\mathrm{Ce}-\mathrm{Yb}$ & $\mathrm{Ce}-\mathrm{Yb}$ & & \\
\hline $\mathrm{H}_{1}$ & $\begin{array}{c}3.77 \\
( \pm 0.14)\end{array}$ & $\begin{array}{l}3.75 \\
( \pm 0.36)\end{array}$ & $\begin{array}{c}3.76 \\
( \pm 0.29)\end{array}$ & 3.57 & 3.68 \\
\hline $\mathrm{H}_{2}$ & $\begin{array}{c}4.40 \\
( \pm 0.16)\end{array}$ & $\begin{array}{c}4.33 \\
( \pm 0.42)\end{array}$ & $\begin{array}{c}4.44 \\
( \pm 0.34)\end{array}$ & 4.33 & 4.51 \\
\hline $\mathbf{H}_{3}$ & $\begin{array}{l}4.40 \\
( \pm 0.16)\end{array}$ & $\begin{array}{l}4.34 \\
( \pm 0.42)\end{array}$ & $\begin{array}{l}4.44 \\
( \pm 0.34)\end{array}$ & 4.34 & 4.49 \\
\hline $\mathrm{H}_{4}$ & $\begin{array}{c}3.74 \\
( \pm 0.14)\end{array}$ & $\begin{array}{c}3.71 \\
( \pm 0.36)\end{array}$ & $\begin{array}{l}3.86 \\
( \pm 0.29)\end{array}$ & 3.78 & 3.83 \\
\hline $\mathrm{H}_{5}$ & $\begin{array}{l}3.74 \\
( \pm 0.14)\end{array}$ & $\begin{array}{l}3.67 \\
( \pm 0.35)\end{array}$ & $\begin{array}{l}3.67 \\
( \pm 0.28)\end{array}$ & 3.49 & 3.50 \\
\hline $\mathrm{H}_{6}$ & $\begin{array}{l}4.33 \\
( \pm 0.16)\end{array}$ & $\begin{array}{c}4.33 \\
( \pm 0.42)\end{array}$ & $\begin{array}{l}4.27 \\
( \pm 0.32)\end{array}$ & 4.13 & 4.35 \\
\hline $\mathrm{C}_{1}$ & $\begin{array}{l}3.45 \\
( \pm 0.13)\end{array}$ & $\begin{array}{l}3.40 \\
( \pm 0.33)\end{array}$ & $\begin{array}{l}3.52 \\
( \pm 0.27)\end{array}$ & - & 3.61 \\
\hline $\mathrm{C}_{2}$ & $\begin{array}{l}3.45 \\
( \pm 0.13)\end{array}$ & $\begin{array}{l}3.39 \\
( \pm 0.33)\end{array}$ & $\begin{array}{l}3.49 \\
( \pm 0.27)\end{array}$ & - & 3.49 \\
\hline $\mathrm{C}_{3}$ & $\begin{array}{c}3.37 \\
( \pm 0.12)\end{array}$ & $\begin{array}{l}3.36 \\
( \pm 0.32)\end{array}$ & $\begin{array}{l}3.30 \\
( \pm 0.25)\end{array}$ & - & 3.25 \\
\hline $\mathrm{C}_{4}$ & $\begin{array}{l}3.21 \\
( \pm 0.12)\end{array}$ & $\begin{array}{l}3.30 \\
( \pm 0.32)\end{array}$ & $\begin{array}{l}3.07 \\
( \pm 0.23)\end{array}$ & - & 3.07 \\
\hline
\end{tabular}

a This work (values calculated using the program PDIGM).

${ }^{b}[10]$, values obtained from the analysis of the corresponding relaxation times (average value of the $\mathrm{Tb}^{3+}, \mathrm{Dy}^{3+}$ and $\mathrm{Ho}^{3+}$ complexes).

c $[21]$.

orientation of the acetate arms relative to the lanthanide ion, giving rise to square quasi-prism $\left(B_{1}\right)$ and square anti-prism coordination (A) geometries (Fig. 1). In both these species there is a water molecule axially bound to the cation. The interconversion process between the two isomers involves an internal torsion (relative to the $\mathrm{N}-\mathrm{C}$ bond) of the acetate pendant groups of the macrocycle. There are, then, two distinct intramolecular dynamic processes in solution, which have been shown to be temperature-dependent [9]: the $\Delta \leftrightarrow \Lambda$ conformational rearrangement of the tetraazacyclododecane ring and the interconversion of the acetate arms, involving internal torsion without bond breaking. From the analysis of the dipolar term of the NMR lanthanideinduced shifts, we verified that a quite good agreement can be achieved between the experimental $G$ values and those calculated for the structures $A$ and $B_{I}$ previously proposed $[9,11]$ (Table 2 ).
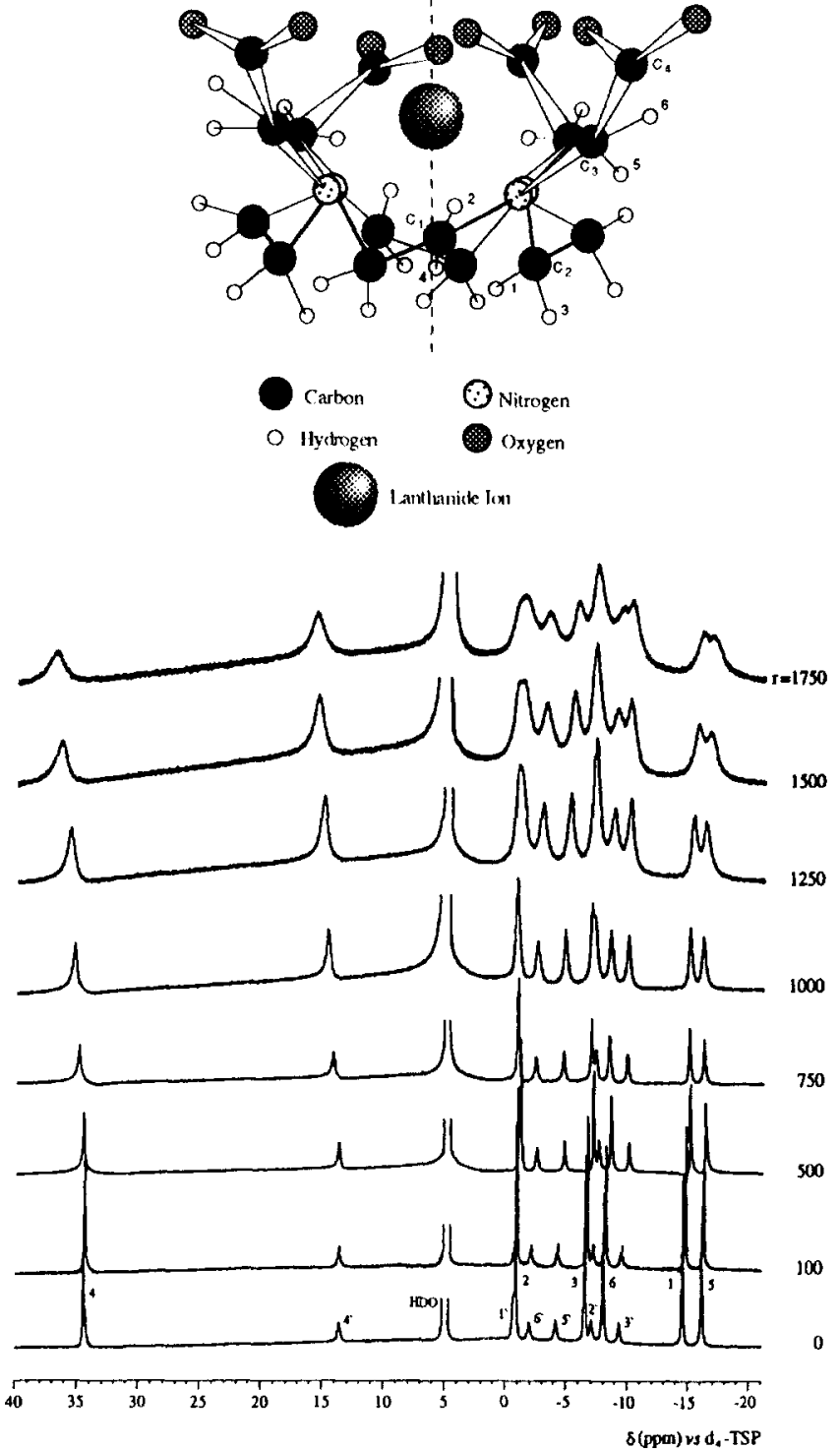

Fig. 2. Proton NMR spectra (11.8 T, $500 \mathrm{MHz})$ of the Eu(DOTA) chelate, in the presence of $\mathrm{LiCl}$. (The experiments were run at 20 ${ }^{\circ} \mathrm{C}$ and $\mathrm{pH}=7$, for a chelate concentration of $0.01 \mathrm{~mol} \mathrm{dm}^{-3} ; r$ represents the [salt]:[chelate] ratio. The protons are named according to the scheme in the upper right-hand corner of the figure).

We considered also an alternative conformation $\left(B_{I I}\right)$ for isomer $\mathrm{B}$, based on a previously forwarded structural model for the Ln(DOTMA) ${ }^{-}$systems [13], having one of the acetate arms uncoordinated to the cation, in a fast exchange situation (at room temperature) with the other carboxylate groups of the ligand (Fig. 1). Interconversion between the four possible $B_{\text {II }}$ forms, involving a consecutive binding and unbinding process (in a rotative way) of each of the four acetate groups to the central ion, is fast on the NMR time-scale (due to the small shift differences observed), and can yield an average structure that deviates only slightly from axial symmetry. Table 2 shows that the agreement factors $(R)$ between the experimental $G$ values for the isomer 
$B$, and those calculated for structures $B_{I}$ and $B_{I I}$ are not statistically different.

We also performed a study, by proton NMR, of the effects of temperature and of the presence of various salts on the conformational equilibria of the $\operatorname{Ln}(\text { DOTA })^{-}$chelates. The analysis of the temperature dependence (between $0{ }^{\circ} \mathrm{C}$ and $30^{\circ} \mathrm{C}$ ) of the concentration ratio ([B]/[A] $)$ of the two isomers of $\mathrm{Yb}(\mathrm{DOTA})^{-}$ led to an estimate of the thermodynamic parameters for this isomerization process, namely $\Delta H^{0}=+13.86$

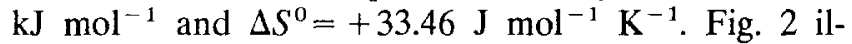
lustrates the nature of the salt effects observed (at constant temperature): for an $[\mathrm{LiCl}]$ to $\left[\mathrm{Eu}(\mathrm{DOTA})^{-}\right]$ ratio equal to or higher than 100 , a clear change in the spectra of $\operatorname{Eu(DOTA)^{-}}$ was detected, with an increase of the isomer $\mathrm{B}$ population. This effect was observed for the $\mathrm{Ce}^{3+}, \mathrm{Eu}^{3+}$ and $\mathrm{Yb}^{3+}$ chelates in the presence of various salts, containing different anions and the same cation (either $\mathrm{Li}^{+}$or $\mathrm{Na}^{+}$), and can be attributed to anion binding to the complexes, either through non-specific ionic strength-related effects or by specific anion binding. We suggest that such binding could induce a change in the lanthanide ion position relative to the plane of the macrocyclic ring (see the decrease of the calculated $d$ values from isomer A to isomer $\mathrm{B}_{\mathrm{I}}$, Table 2), simultaneously with a variation of the orientation of the acetate arms relative to the ring, consequently favouring the isomeric species $B_{1}$.

The presence of the $\mathrm{B}$ isomer in solution is, then, favoured both by a temperature increase and by anion binding.

\section{Conclusion}

The study of the Ln(DOTA $)^{-}$chelates in aqueous solution, by NMR spectroscopy, evidences the existence of two distinct isomeric forms, unlike the case of the $\operatorname{Ln}(\text { DOTP })^{5-}$ complexes, for which there is only one possible conformation in solution. Analysis of the dipolar term of the observed proton LIS is consistent with the previous proposal of structures $A$ and $B_{I}$ (Fig. 1) for the two $\operatorname{Ln}(\mathrm{DOTA})^{-}$isomers $[9,10]$, but cannot statistically distinguish between an octadentate $\left(\mathrm{B}_{1}\right)$ and an heptadentate $\left(B_{I I}\right)$ [13] coordination of the DOTA ligand in isomer $\mathrm{B}$. This species is favoured, in aqueous solution, by a temperature increase and by anion binding. The proposed model, based on isomers $A$ and $B_{I}[9,11]$ has recently got support from the observation, by $\mathrm{X}$-ray crystallographic studies, of both structures A and $B_{I}$ in the same crystal of $\operatorname{Gd}(D O 3 M A)$ $\left(\mathrm{DO} 3 \mathrm{MA}=(1 \mathrm{R}, 4 \mathrm{R}, 7 \mathrm{R})-\alpha, \alpha^{\prime}, \alpha^{\prime \prime}\right.$-trimethyl-1,4,7,10-tetraazacyclododecane-1,4,7-triacetic acid) [20] and of a
$\mathrm{B}_{\mathrm{I}}$-type coordination mode in the Eu(THP) complex (THP $=1,4,7,10$-tetraazacyclododecane- $N, N^{\prime}, N^{\prime \prime}, N^{\prime \prime \prime}$-tetrakis(2-hydroxypropyl) [21].

However, further studies on the structure and dynamics of the $\operatorname{Ln}(\mathrm{DOTA})^{-}$isomerization process in aqueous solution are needed, namely the investigation of the effect of high pressure on the NMR spectra of this system (in the presence and absence of different salts).

\section{Acknowledgements}

C.F.G.C.G. and M.P.M.M. acknowledge support from JNICT (Portugal) (Grant PBIC/S/SAU/1623/92) and A.D.S. from the Robert Welsh Foundation (Texas, USA). This work has been performed within the European COST D1 Action (Project D1/0001/92).

\section{References}

[1] R.D. Hancock and A.E. Martell, Chem. Rev., 89 (1989) 1875.

[2] J.F. Desreux and P.P. Barthelemy, Nucl. Med. Biol, 15 (1988) 9.

[3] C.F.G.C. Geraldes, A.D. Sherry, R.D. Brown III and S.H. Koenig, Magn. Res. Med., 3 (1986) 242.

[4] M. Magerstadt, O.A. Gansow, M.W. Brechbiel, D. Colcher, L. Baltzer, R.H. Knop, M.E. Girton and M. Naegele, Magn. Res. Med., 3 (1986) 808.

[5] K. Kumar and M.F. Tweedle, Pure Appl. Chem., 65 (1993) 515.

[6] M.F. Loncin, J.F. Desreux and E. Merciny, Inorg. Chem., 25 (1986) 2646.

[7] F. Inagaki and T. Miyazawa, Progr. NMR Spec., 14 (1981) 67.

[8] J.F. Desreux, Inorg. Chem., 19 (1980) 1319.

[9] S. Aime, M. Botta and G. Ermondi, Inorg. Chem., 31 (1992) 4291.

[10] S. Aime, L. Barbero, M. Botta and G. Ermondi, J. Chem. Soc. Dalton Trans. (1992) 225.

[11] S. Hoeft and K. Roth, Chem. Ber., 126 (1993) 869.

[12] M. Albin, W. De W. Horrocks Jr and F.J. Liotta, Chem. Phys. Lett., 85 (1982) 61.

[13] H.G. Brittain and J.F. Desreux, Inorg. Chem., 23 (1984) 4459

[14] R. Delgado and J.J.R. Fraústo da Silva, Talanta, 29 (1982) 815.

[15] A.D. Sherry and E. Pascual, J. Am. Chem. Soc., 99 (1977) 5871.

[16] C.F.G.C. Geraldes, A.D. Sherry and G.E. Kiefer, J. Magn. Res., 97 (1992) 290.

[17] C.N. Reilley, B.W. Good and J.F. Desreux, Anal. Chem., 47 (1975) 2110.

[18] C.N. Reilley, B.W. Good and R.D. Allendoerfer, Anal. Chem., 48 (1976) 1446.

[19] M.R. Spirlet, J. Rebizant, J.F. Desreux and M.F. Loncin, Inorg. Chem., 23 (1984) 359.

[20] S.I'. Kang, R.S. Ranganathan, J.E. Emswiler, K. Kumar, J.Z. Gourgoutas, M.F. Malley and M.F. Tweedle, Inorg. Chem., 32 (1993) 2912.

[21] K.O. Chin, J.R. Morrow, C.H. Lake and M.R. Churchill, Inorg. Chem., 33 (1994) 656. 